\title{
Oficinas vivenciais: reflexões sobre direitos humanos de pessoas com deficiências
}

\author{
Ana Luiza de Mendonça Oliveira \\ Universidade Federal de Uberlândia - Uberlândia - MG - Brasil \\ Marineia Crosara de Resende \\ Universidade Federal de Uberlândia - Uberlândia - MG - Brasil
}

\begin{abstract}
Resumo
Considerando o aumento da atenção para a inclusão da pessoa com deficiência na sociedade, torna-se fundamental para os futuros professores, ou seja, os alunos dos cursos de licenciatura, compreenderem como as pessoas com deficiência percebem sua vida, se ajustam, vivem o dia a dia e participam da vida em comunidade. Este trabalho se propõe a relatar as Oficinas Vivenciais do projeto "Vivenciando a Deficiência: (des) educando para incluir", realizada junto a 638 alunos matriculados na disciplina Psicologia da Educação, na Universidade Federal de Uberlândia (MG). As Oficinas foram realizadas por meio da vivência de simulação das deficiências, com os participantes se colocando no lugar do outro, com equipamentos que simulam deficiências visuais e/ou auditivas. Na avaliação final, ficou explícito o compromisso em serem multiplicadores de acessibilidade e a necessidade de disciplinas que trabalhem os Direitos Humanos, especificamente, das pessoas com deficiência para a quebra de estereótipos.
\end{abstract}

Palavras-chave: Inclusão; Direitos Humanos; Psicologia Educacional.

\section{Experiential workshops: reflections on human rights of persons with disabilities}

\begin{abstract}
Considering the increased attention to the inclusion of persons with disabilities in society, it is essential for future teachers, students of undergraduate programs, understand how people with disabilities realize their life, fit, day to day living and participate of community life. This study aims to report the experiential workshops, the project "Experiencing Disability: (mis) educating to include" held by the 638 students enrolled in the course Educational Psychology at the Federal University of Uberlândia (MG). The workshops were conducted by the experience simulation of disabilities, with participants putting themselves in another's place, with equipment that simulate visual and / or hearing impairments. In the final assessment, it is explicit, the commitment to be multipliers of accessibility and the need for disciplines that work Human Rights, specifically for people with disabilities to break stereotypes.
\end{abstract}

Keywords: Inclusion, Human Rights, Educational Psychology.

\section{Talleres vivenciales:}

\section{reflexiones sobre derechos humanos de personas con deficiencias}

\section{Resumen}

Considerando el aumento de la atención para la inclusión de la persona con deficiencia en la sociedad, se vuelve fundamental a los futuros profesores, alumnos de los cursos de licenciatura, comprender como las personas con deficiencia perciben su vida, se ajustan, viven el día a día y participan de la vida en comunidad. Ese estudio se propone a relatar los Talleres vivenciales, del proyecto "Vivenciando la Deficiencia: (des)educando para incluir", realizada junto a 638 alumnos ingresados en la asignatura Psicología de la Educación, en la Universidad Federal de Uberlândia (MG). Se realizaron los Talleres por intermedio de la vivencia de simulación de las deficiencias, con los participantes colocándose en el lugar del otro, con equipajes que simulen deficiencias visuales y/o auditivas. En la evaluación final, quedó explícito, el compromiso en ser multiplicadores de accesibilidad y la necesidad de asignaturas que trabajen los Derechos Humanos, específicamente, de las personas con deficiencia para la quiebra de estereotipos.

Palabras clave: Inclusión; Derechos Humanos; Psicología Educacional. 
"A utopia está lá no horizonte.

Me aproximo dois passos, ela se afasta dois passos. Caminho dez passos e o horizonte corre dez passos. Por mais que eu caminhe, jamais alcançarei.

Para que serve a utopia?

Serve para isso: para que eu não deixe de caminhar".

Galeano (2007)

\section{Introdução}

Com o objetivo de proporcionar uma reflexão sobre a vida das pessoas com deficiência, por meio do olhar para o cotidiano urbano e da sala de aula, o projeto aqui relatado apresenta-se como uma estratégia na criação de um espaço de aprendizado para o respeito ao mundo plural em que vivemos para a valorização da diferença para a convivência, para que as mudanças se efetivem em um mundo de todos e para todos por meio de Oficinas Vivenciais. A realização dessas oficinas de vivência das deficiências junto a alunos de licenciaturas surge como forma de sensibilização à adoção de medidas de eliminação de barreiras e adaptações para inserção de pessoas com deficiência nos espaços sociais e educacionais, bem como possibilitar aos futuros professores conhecer a realidade relacionada às pessoas com deficiência.

O segmento das pessoas com deficiência reúne em uma mesma categoria vários tipos de deficiência física, auditiva, visual, intelectual e mental, constituindo assim um grupo bastante heterogêneo (Cruz \& Emmel, 2013) e encontram-se inseridas em contextos sociais bastante diversos (Bernardes, Maior, Spezia, \& Araujo, 2009). É preciso a adoção de estratégias para levar as pessoas à compreensão das inúmeras dificuldades que as pessoas com deficiência passam para melhor entendimento sobre a necessidade de preparar um mundo que contemple a diversidade através da inclusão social e seja acessível a todos.
De acordo com Sassaki (2003), a inclusão social pode ser entendida como um processo pelo qual a sociedade se adapta para poder incluir não só pessoas com deficiência, mas todas as pessoas, para que tenham seu direito de ir e vir assegurado. A inclusão constitui-se como um processo bilateral, no qual as pessoas ainda excluídas e a sociedade buscam, de forma conjunta, resolver os problemas, decidir sobre soluções e efetivar a equiparação de oportunidades para todos. Desta forma, as pessoas com deficiência podem se preparar para assumirem seus papéis de protagonistas de sua vida.

Para Silva e Miranda (2012), a inclusão representa um novo paradigma que considera a inserção total e incondicional das diferenças na sociedade, apontando para a necessidade de adequação da sociedade. Foucault (1987) aponta que: "A inclusão é um processo de disciplinarização dos excluídos, portanto, um processo de controle social e manutenção da ordem na desigualdade social" (p. 58).

Historicamente, as pessoas com deficiência foram marcadas pela negligência, omissão e segregação, o que interiorizou em nossa sociedade o preconceito e as atitudes discriminatórias. A sociedade, até então, tende a perceber a deficiência como uma doença crônica, e o "deficiente" como inválido e incapaz, uma vez que ele pouco pode contribuir para a economia e para a sociedade (Silva \& Miranda, 2012). Nesse sentido perpetuou-se por longo tempo o "ciclo da invisibilidade" (Werneck, citado por Almeida, 2010).

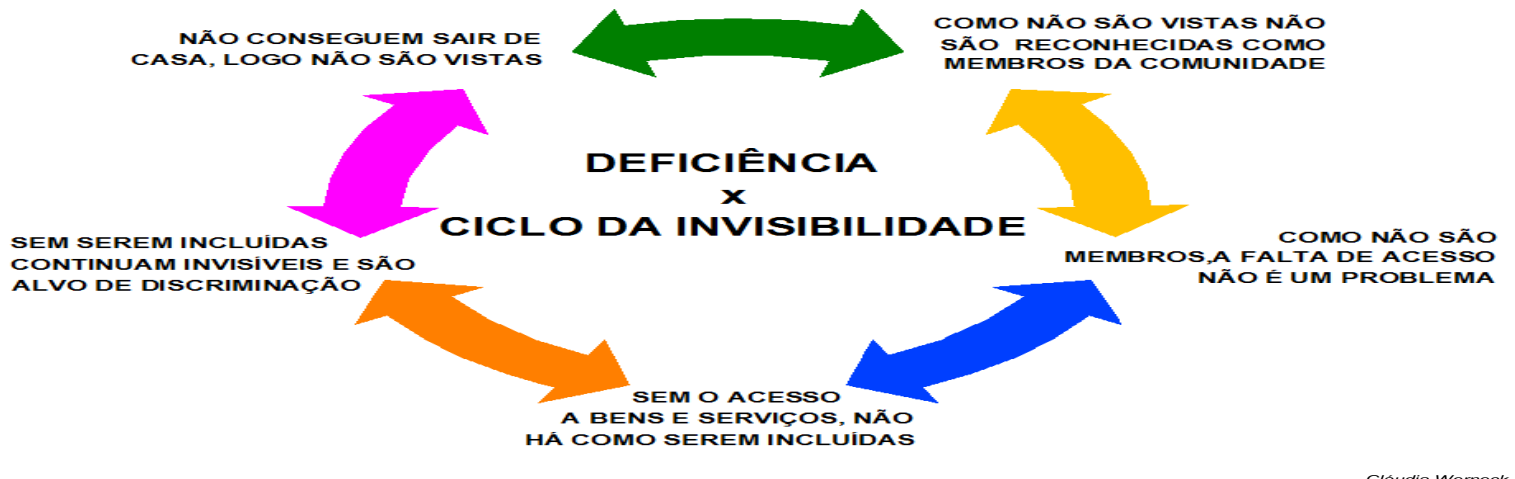

Figura 1. Diagrama com setas no movimento circular apresentando as seguintes palavras: pessoas com deficiência não conseguem sair de casa e, logo, não são vistas pela comunidade; como não são vistas, não são reconhecidas como membros da comunidade; como não são membros, a falta de acesso não é um problema; sem o acesso a bens e serviços, não há como serem incluídas; sem serem incluídas, continuam invisíveis e são alvo de discriminação. 


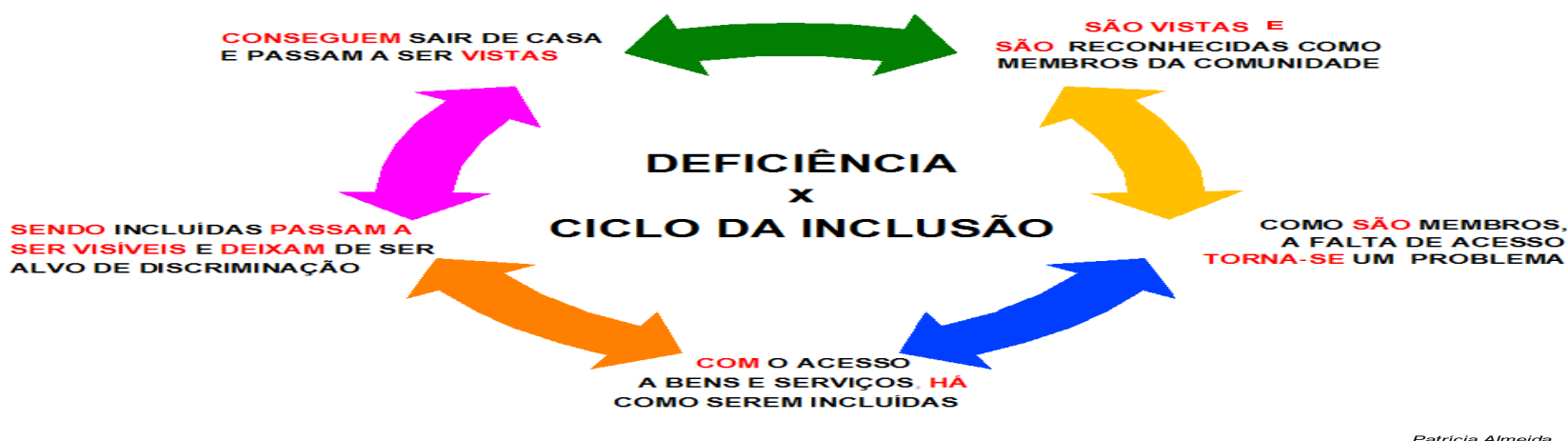

Figura 2. Diagrama com setas no movimento circular apresentando as seguintes palavras: pessoas com deficiência conseguem sair de casa e, logo, são vistas e reconhecidas como membros da comunidade; como são membros da comunidade a falta de acesso torna-se um problema; com o acesso a bens e serviços, há como serem incluídas; sendo incluídas passam a ser visíveis e deixam de ser alvo de discriminação.

A relação da sociedade com a parcela da população constituída pelas pessoas com deficiência tem se modificado no decorrer dos tempos, tanto no que se refere aos pressupostos filosóficos, que a determinam e permeiam, como no conjunto de práticas nas quais ela se objetiva (Aranha, 2012), dando lugar ao "ciclo da inclusão" (Almeida, 2010).

É importante fazer um breve histórico sobre as atitudes da sociedade em relação à deficiência. De acordo com Kirk e Gallagher (1996), podem ser reconhecidos quatro estágios dessas atitudes. Na era pré-cristã, tendia-se a negligenciar e a maltratar as pessoas com deficiências. $\mathrm{Na}$ Antiguidade, por não corresponderem aos padrões estéticos, muitas dessas pessoas foram abandonadas ou eliminadas da sociedade. Com a difusão do Cristianismo, na Idade Média, a deficiência viveu momentos ambivalentes. Em determinados momentos, as pessoas com deficiência eram consideradas criaturas divinas, que não poderiam ser desprezadas ou abandonadas por possuírem alma. Mas em outros, representavam forças malignas e, por isso, deveriam ser eliminadas. Essa época foi marcada por atitudes paradoxais que transitavam entre a proteção e a eliminação, sobressaindo a visão do aspecto sobrenatural. No século XVI houve um redimensionamento do modo de pensar e de ver a deficiência, passando a existir diversas visões sobre as pessoas com deficiência até chegar-se ao movimento de Inclusão Social (Silva \& Miranda, 2012), permeada pelos direitos humanos.

Resende, Costa e Resende (2012) destacam que historicamente os direitos humanos das pessoas com deficiência passaram por quatro fases: a) fase de intolerância em relação às pessoas com deficiência, em que a deficiência simbolizava impureza, ou mesmo castigo divino, b) fase de invisibilidade: marcada pela invisibilidade das pessoas com deficiência, c) fase assistencialista: orientada por uma ótica assistencialista, pautada na perspectiva médica e biológica de que a deficiência era uma "doença a ser curada", sendo o foco centrado no indivíduo "portador da enfermidade", e d) fase de direitos humanos: orientada pelo paradigma dos direitos humanos, em que emergem os direitos à inclusão social, com ênfase na relação da pessoa com deficiência e do meio em que ela se insere, bem como na necessidade de eliminar obstáculos e barreiras superáveis, sejam elas culturais, físicas ou sociais, que impeçam o pleno exercício dos direitos humanos.

Essa trajetória tem marcas históricas, quando, por exemplo, a Organização das Nações Unidas (ONU) proclamou a Declaração Universal de Direitos Humanos, em 1949. Um documento marco na história dos direitos humanos, para reforçar as ideias de liberdade e igualdade, mas que deixou de fora as pessoas com deficiência, já que sem acessibilidade não há garantia ao que é considerado direito universal (direito à vida e à liberdade, à liberdade de opinião e de expressão, o direito ao trabalho e à educação, entre muitos outros) (Resende, 2016), perpetuando a marca da diferença através do estigma e um direito elitizado.

De acordo com Goffman (1988), o estigma pode ser pensado como um selo, o rótulo que uma dada pessoa ou grupo aplica sobre outra pessoa ou grupo e, assim, inerente a preconceitos e estereótipos, o estigma só existe e só se manifesta nas relações humanas. Ou seja, o estigma não é uma referência a determinadas características, mas sim à leitura social que delas é feita no contexto das relações interpessoais. Amaral (2002) aponta que algumas consequências drásticas advêm quando o estigma está presente: desumanização/ coisificação daquele que o recebe e há uma potencialização daquele que o impinge. Ou seja, um sentimento de superioridade. Ao primeiro cabe o lugar da falta, da falha e do erro, ao segundo, o da completude e do acerto.

Para Caniglia (2008), quando se fala em inclusão social, fala-se também em exclusão social que compreende todas as pessoas até então excluídas dos sistemas sociais comuns. Também denominados como grupos "minoritários", essas pessoas deverão ser incluídas pela mudança de paradigma da Inclusão Social, onde a sociedade se forma para 
adaptar às necessidades das pessoas. Ainda de acordo com a autora, antes do paradigma da inclusão social, a sociedade ditava o padrão a ser seguido e todos procuravam se adaptar à norma. No novo paradigma as diferenças são bem vindas (devem ser) e trazem a marca da diversidade. A padronização e massificação do paradigma antigo dão lugar à convivência com as diferenças de valores, crenças, costumes, hábitos e singularidades.

Para que se tenha a inclusão de fato, é necessário que a sociedade se modifique, a partir do entendimento de que ela é que precisa ser capaz de atender às necessidades de seus cidadãos. Assim, o desenvolvimento das pessoas com deficiência (por meio da educação, reabilitação e qualificação profissional), deve ocorrer dentro do processo de inclusão, e não funcionar como um pré-requisito, para que elas façam parte da sociedade (Sassaki, 2010).

De acordo com Aranha (2012), a inclusão social é um processo que diz respeito a todos os cidadãos, inclusive as pessoas com deficiência. Segundo o autor, para que a inclusão das pessoas com deficiência se efetive, será necessária uma sociedade inclusiva, realmente democrática, onde impere a liberdade de toda e qualquer pessoa se manifestar, em igualdade de condições, nas diferentes instâncias de debate e de tomada de decisões dessa sociedade, disponibilizando os suportes necessários para viabilizar essa participação.

A Inclusão Social é uma ação social que integra as diversas áreas das ciências e os diversos segmentos sociais, em um movimento conjunto de toda a sociedade para uma atitude inclusiva de mudança. É uma condição de todas as pessoas para que possam exercer sua cidadania. A cidadania por sua vez, é direito e é dever. Assim, todos são iguais no que se refere aos direitos e são diferentes no que se referem às suas características, dons, aptidões, habilidades, competências, enfim, suas singularidades. As pessoas devem ser reconhecidas, portanto, pelo papel que desempenham na sociedade (Caniglia, 2008).

Aranha (2012) aponta que não adianta prover igualdade de oportunidades se a sociedade não garantir o acesso da pessoa com deficiência a essas oportunidades. Muitos são os suportes necessários e possíveis de imediato. Outros demandam maior planejamento a médio e longo prazos. Todos, entretanto, devem ser disponibilizados, caso se pretenda alcançar uma sociedade justa e democrática.

No movimento da inclusão, a pessoa é vista como potencialidade e há um esforço social para ajudá-la a desenvolver seu potencial. Assim, para pensar em inclusão é fundamental romper com o conceito de normal como igual e adotar que normal é a diversidade (Abenhahim, 2005). De acordo com Veiga Neto (2005, p. 58): "Diferença não é antônimo de igualdade. O contrário da diferença é a mesmice, o contrário de igualdade é desigualdade. Queremos a igualdade, mas ao mesmo tempo nós queremos manter as diferenças".

A construção de uma verdadeira sociedade inclusiva passa também pelo cuidado com a linguagem, o termo correto é pessoas com deficiência (Sassaki, 2003). Assim reconhecida na Convenção sobre os Direitos das Pessoas com Deficiência (Resende \& cols, 2012), que confere re- conhecimento universal à dignidade das pessoas com deficiência, ressaltando que a deficiência é apenas mais uma característica de seres humanos livres e iguais em direitos e obrigações.

A Convenção sobre os Direitos das Pessoas com Deficiência (Resende \& cols., 2012), no seu preâmbulo aponta, dentre outras, as seguintes diretrizes: c) Reafirmando a universalidade, a indivisibilidade, a interdependência e a inter-relação de todos os direitos humanos e liberdades fundamentais, bem como a necessidade de garantir que todas as pessoas com deficiência os exerçam plenamente, sem discriminação; e) Reconhecendo que a deficiência é um conceito em evolução e que a deficiência resulta da interação entre pessoas com deficiência e as barreiras devidas às atitudes e ao ambiente que impedem a plena e efetiva participação dessas pessoas na sociedade em igualdade de oportunidades com as demais pessoas,...; g) Ressaltando a importância de trazer questões relativas à deficiência ao centro das preocupações da sociedade como parte integrante das estratégias relevantes de desenvolvimento sustentável; h) Reconhecendo também que a discriminação contra qualquer pessoa, por motivo de deficiência, configura violação da dignidade e do valor inerentes ao ser humano; i) Reconhecendo ainda a diversidade das pessoas com deficiência; j) Reconhecendo a necessidade de promover e proteger os direitos humanos de todas as pessoas com deficiência, inclusive daquelas que requerem maior apoio; k) Preocupados com o fato de que, não obstante esses diversos instrumentos e compromissos, as pessoas com deficiência continuam a enfrentar barreiras contra sua participação como membros iguais da sociedade e violações de seus direitos humanos em todas as partes do mundo,...; m) Reconhecendo as valiosas contribuições existentes e potenciais das pessoas com deficiência ao bem-estar comum e à diversidade de suas comunidades, e que a promoção do pleno exercício, pelas pessoas com deficiência, de seus direitos humanos e liberdades fundamentais e de sua plena participação na sociedade resultará no fortalecimento de seu senso de pertencimento à sociedade e no significativo avanço do desenvolvimento humano, social e econômico da sociedade, bem como na erradicação da pobreza; n) Reconhecendo a importância, para as pessoas com deficiência, de sua autonomia e independência individuais, inclusive da liberdade para fazer as próprias escolhas; w) Conscientes de que a pessoa tem deveres para com outras pessoas e para com a comunidade a que pertence e que, portanto, tem a responsabilidade de esforçar-se para a promoção e a observância dos direitos reconhecidos na Carta Internacional dos Direitos Humanos.

A proposta das Oficinas Vivenciais surge com o intuito de que as pessoas tenham conhecimento sobre a Convenção dos Direitos das Pessoas com Deficiência (Resende \& Vital, 2008) - documento criado pela ONU e ratificado no Brasil, com valor de emenda constitucional em 2008 -, com o lema "Nada sobre nós, sem nós" a partir da ótica das próprias pessoas com deficiência, já que são elas que sabem o que é melhor para elas, e por isso, devem ser ouvidas em todas as 
ações que as envolvam. A Convenção possibilitará a qualquer cidadão brasileiro conhecer de maneira clara, objetiva e elucidativa os direitos das pessoas com deficiência (Baroni, 2008).

A partir da Convenção, surge em 06 de julho de 2015, a Lei Brasileira de Inclusão (LBI), entrando em vigência em janeiro de 2016. A LBI é uma legislação que tenta regulamentar a Convenção, e propõe desafios para alcançar os objetivos do milênio (até 2030), entre eles "assegurar educação inclusiva de qualidade e promover oportunidades de aprendizado ao longo de toda a vida, incluindo a formação profissionalizante" (Silva, 2015).

Além de serem obras de suma importância para todos os representantes legais, na esfera executiva, legislativa e judiciária, em seus três níveis - municipal, estadual e federal - pois a partir do conhecimento deles sobre a Convenção e a LBI, poderá se garantir a efetiva mudança do paradigma do modelo médico para o modelo social da deficiência, um dos maiores avanços alcançados pela Convenção. A Convenção, somada a todos os demais documentos já existentes na área dos direitos humanos das pessoas com deficiência, torna-se mais um forte instrumento de ação política na medida em que agrega às legislações um instrumento de pesquisa, conhecimento e ação. E principalmente para as pessoas com deficiência como uma ferramenta de garantia de autonomia, a partir de ações eficazes de transformação social (Resende \& Vital, 2008).

Para que o paradigma da inclusão social aconteça de fato, a sociedade brasileira ainda precisa tornar sua prática consistente com seu discurso legal. Há que buscar soluções para a convivência na diversidade que a caracteriza, enriquece, dá sentido e significado. Há que efetivamente favorecer a convivência e a familiaridade com as pessoas com deficiência, derrubando as barreiras físicas, sociais, psicológicas e instrumentais que as impede de circular no espaço comum (Aranha, 2012).

Glat e Pletsch (2011) salientam que com o discurso da inclusão demarcado nos documentos legais, os alunos com deficiência estão indo para as escolas regulares em turmas comuns, mas pesquisas realizadas pelas autoras no contexto educacional revelaram que essa população tem sido considerada quase que exclusivamente responsabilidade da equipe de educação especial, seja dentro ou fora da escola regular. As autoras explicam "o aluno está incluído fisicamente na turma comum e pode até ter uma boa integração social com colegas, mas fica excluído do processo ensino-aprendizagem" (p. 31). Diante desta questão temos a exclusão em torno do processo de inclusão, acontecendo concomitantemente, já que estes alunos estão à parte daquilo que deveriam ser incluídos que é a construção de conhecimento.

Os professores têm um papel fundamental nesse processo de combate à exclusão por meio da educação inclusiva, que é uma abordagem que procura responder às necessidades de aprendizagem de todas as pessoas, independente da fase de desenvolvimento, crianças, jovens e/ ou adultos, trazendo oportunidade para aqueles que estão vulneráveis à marginalização e excluídos. Nesta perspecti- va, independente das condições que a pessoa apresenta, físicas, intelectuais, sociais, emocionais, linguísticas e outras, houve o desenvolvimento de sistemas educacionais inclusivos, no qual as escolas devem acolher todas as crianças, atendendo suas especificidades (Resende, 2016).

\section{O projeto "Vivenciando a Deficiência: (des) educando para incluir"}

O projeto aconteceu durante quatro semestres letivos, nos anos 2014 e 2015, na Universidade Federal de Uberlândia (UFU), com o objetivo de proporcionar aos alunos de cursos de licenciaturas que estivessem cursando a disciplina Psicologia da Educação, novas perspectivas e reflexões no que diz respeito a viver com uma deficiência e proporcionar uma experiência na qual possibilite ao futuro professor, (re)pensar sua prática profissional. O projeto foi desenvolvido através de uma parceria entre o Instituto de Psicologia, da UFU e a Associação dos Paraplégicos de Uberlândia (APARU).

Vale ressaltar que a APARU trabalha com questões relacionadas à deficiência física desde 1979, por isso também esse nome histórico, e tem entre seus principais objetivos promover para e com as pessoas com deficiência física o respeito e a convivência, a promoção humana, a capacitação profissional, a habilitação e a reabilitação, as atividades físicas e desportivas e à cidadania. Conta com aproximadamente mil e oitocentos associados frequentes, para os quais oferece atendimento em vários setores, como psicologia, serviço social, odontologia, fisioterapia, jurídico, entre outros para que a inclusão seja realidade em Uberlândia (Resende, 2004).

Os alunos dos cursos de licenciatura, matriculados na disciplina de Psicologia da Educação, foram convidados a participar da Oficina Vivencial para que pudessem vivenciar uma deficiência, e a partir desta experiência, se colocar no lugar do outro e, assim, pensar nas possibilidades de atuação profissional frente à diversidade. Em três semestres foram realizadas oficinas com os alunos dos cursos de Letras (diurno e noturno), Matemática, Ciências Biológicas (diurno e noturno), Educação Física, Artes Visuais (diurno e noturno), Filosofia (diurno e noturno), História (diurno e noturno) e Enfermagem. No total, participaram da vivência 638 alunos.

Antes de realizarem as oficinas, os estagiários do projeto, sob supervisão de uma professora com deficiência, participaram de treinamento vivencial na APARU, em que a supervisora de estágio e os profissionais da Associação mostraram como é feita a paramentação das pessoas para participarem da Oficina, de forma correta, a fim de evitar lesões. A partir da vivência das deficiências foram discutidas com os envolvidos no projeto as possibilidades das oficinas, a realidade das pessoas com deficiência, a Convenção sobre os Direitos das Pessoas com Deficiência e como foi a experiência vivida na APARU. A partir dessa vivência, os estagiários passariam a ser "multiplicadores" dessa experiência de inclusão. 
Para começar a fazer as vivências com os alunos dos respectivos cursos, entrou-se em contato com os professores responsáveis por cada disciplina de Psicologia da Educação oferecida no semestre, que disponibilizaram uma de suas aulas de quatro horários para a realização das Oficinas. No dia disponibilizado, os estagiários realizaram as oficinas no Campus em que a disciplina acontecia. Os estagiários se dividiram em grupos de acordo com o número de participantes de cada Oficina.

A Oficina era conduzida por um(a) coordenador(a), um(a) co-coordenador(a) e oficineiros, todos estagiários. A coordenação se responsabilizava pela apresentação da Oficina e por organizar a discussão, os oficineiros pela paramentação e acompanhamento dos participantes no trajeto da atividade. A oficina foi dividida em três momentos: O primeiro momento consistia na apresentação dos objetivos, do convite à participação, da justificativa para a realização das oficinas e de uma apresentação da Convenção sobre os Direitos das Pessoas com Deficiência. Em seguida, os alunos que aceitaram participar eram paramentados para a parte vivencial, onde faziam um percurso dentro da universidade, observando as barreiras que surgiam no caminho. Como parte da paramentação, os participantes utilizavam materiais como faixas, muletas, bengalas, protetor auricular, cadeiras de rodas, vendas, óculos, entre outros. Após o percurso, os alunos eram convidados a discutir como havia sido a experiência e como esta poderia auxiliá-los em suas práticas profissionais como futuros professores. Após a discussão e avaliação conjunta das Oficinas, finalizava-se com a leitura do texto "O Apartheid contra a pessoa com deficiência" (Resende, 2008).

\section{Considerações finais}

Acreditamos que os objetivos deste trabalho foram alcançados. A partir da avaliação final dos participantes, que relataram ter encontrado na experiência formas de pensar e repensar as questões relacionadas às pessoas com deficiência, especialmente as concernentes às barreiras físicas e atitudinais, produzindo a capacidade de exercer a empatia e desta forma, buscar formas de refletir e repensar o cotidiano. Vários alunos relataram que não haviam percebido questões relativas à acessibilidade na Universidade e/ou em outros espaços de uso público. Percebe-se que a vivência pode proporcionar outros olhares em relação à acessibilidade e aos direitos humanos das pessoas com deficiência.

A atividade prática despertou novas perspectivas, por meio do olhar ao cotidiano urbano e a sala de aula, sensibilizando-os no que diz respeito a viver com uma deficiência. Os participantes da oficina puderam vivenciar a(s) deficiência(s), passando por dificuldades e desafios frequentes no dia a dia das pessoas com deficiência. Os participantes falaram de acessibilidade, disseram que a universidade e a sociedade, em geral, não estão preparadas para atender a demanda das pessoas com deficiência, perceberam o quanto chamaram a atenção enquanto realizavam o percurso. Esta ativi- dade realizada com alunos dos cursos de licenciatura é uma possibilidade de apresentar um novo olhar sobre a vida das pessoas (com deficiência), e ao se colocar no lugar do outro, é possível ter uma postura crítica sobre sua futura atuação.

Foram discutidos alguns aspectos da Convenção, quando os participantes relataram alguns casos com que tiveram contato e debateram sobre a legislação. Relataram o quanto chamaram a atenção, enquanto realizavam o percurso, pela diferença explícita que se fazia ver e sentir naquele momento, passando pelos mesmos estigmas das pessoas com deficiência. Parece clara a importância de um espaço para a reflexão e a informação sobre inclusão, acessibilidade e diversidade, tendo em vista o quanto as pessoas ainda desconhecem os direitos das pessoas com deficiência.

$\mathrm{Na}$ avaliação final, ficou explícito, por meio da fala dos alunos participantes, o compromisso de serem multiplicadores de acessibilidade e a necessidade de disciplinas que trabalhem os Direitos Humanos, especificamente, das pessoas com deficiência, para a quebra de estereótipos. No Brasil, ainda as mudanças são pautadas em questões econômicas e nesse sentido a inclusão fica sendo mais um paradigma a ser vencido, que só será efetivada quando o direito à diferença e à plena cidadania se concretizarem de fato.

\section{Referências}

Abenhahim, E. (2005). Os caminhos da inclusão: breve histórico. Em A. M. Machado (Org.), Psicologia e Direitos humanos: Educação Inclusiva - Direitos Humanos na Escola. São Paulo: Casa do Psicólogo.

Almeida, P. (2010). Comunicação e a Convenção sobre os Direitos das pessoas com deficiência. Recuperado: 03 nov. 2015. Disponível:http://www.inclusive.org.br/wp-content/ uploads/2010/12/Comunicacao-e-a-Convencao-0612.ppt.

Amaral, L. A. (2002). Diferenças, Estigma e preconceito: o desafio da inclusão. Em M. K. Oliveira, D. T. R. Souza, \& T. C. Rego (Orgs), Psicologia, Educação e as Temáticas da vida contemporânea (pp. 233-248). São Paulo: Moderna.

Aranha, M. S. F. (2012). Paradigmas da relação da sociedade com as pessoas da deficiência. Revista Brasileira de Psicologia Ciência e Profissão, 2(18), 01-12.

Baroni, A. C. (2008). Prefácio. Em A. P. C. Resende \& F. M. P. Vital (Orgs.),A convenção sobre os Direitos das Pessoas com deficiência comentada(pp. 7-8). Brasília-DF: Coordenadoria Nacional para Integração da Pessoa Portadora de Deficiência CORDE.

Bernardes, L. C. G., Maior, I. M. M. L, Spezia, C. H., \&Araujo, T. C. C. F. (2009). Pessoas com deficiência e políticas de saúde no Brasil: reflexões bioéticas. Ciência \& Saúde Coletiva, 14(1), 31-38.

Caniglia, M. (2008). Direitos humanos, diversidade e inclusão social: 
o olhar da Terapia Ocupacional. UFMG: Núcleo de estudos de Terapia Ocupacional do Centro Oeste Mineiro.

Cruz, D. M. C. \& Emmel, M. L. G. (2013). Associação entre papéis ocupacionais, independência, tecnologia assistiva e poder aquisitivo em sujeitos com deficiência física. Revista LatinoAmericana Enfermagem, 21(2), 484-491.

Galeano, E. (2007). Janela sobre a utopia. Em E. Galeano, As palavras andantes (p. 310). Porto Alegre: L\&PM.

Foucault, M. (1987). As palavras e as coisas: uma arqueologia das ciências humanas. São Paulo: Martins Fontes.

Glat, R. \& Pletsch, M. D. (2011). Inclusão Escolar de Alunos com necessidades Especiais. Rio de janeiro: EDUERJ.

Goffman, E. (1988). Estigma: notas sobre a manipulação da identidade deteriorada. São Paulo: LTC.

Kirk, S. A. \& Gallagher, J. J. (1996). Educação da criança excepcional. São Paulo: Martins e Fontes.

Organização das Nações Unidas [ONU] (1948). Adotada e proclamada pela resolução 217 A (III) da Assembleia Geral das Nações Unidas em 10 de dezembro de 1948. Recuperado: 03 nov. 2015. Disponível: www.direitoshumanos.usp.br.

Resende, A. P. C. (2004). Todos na Cidade: o direito a acessibilidade das pessoas com deficiência física em Uberlândia. Uberlândia: EDUFU.

Resende, A. P. C. (2008). O apartheid contra as pessoas com deficiência. Arquivo pessoal. Recuperado: 03 nov. 2015. Disponível: https://www.facebook.com/notes/marineia-crosara-deresende/apartheid-contra-a-pessoa-com-defici\%C3\%AAncia-porana-paula-crosara-de-resende-2008/10203267798850594
Resende, A. P. C., Costa, R. S., \& Resende, M. C. (2012). Deficiência: a revolução de um paradigma para reafirmar direitos. Em R. M. Corrêa. (Org.), O discurso sobre o outro e as práticas sociais. (pp. 53-76). Belo Horizonte: Editora PUCMINAS.

Resende, M. C. (2016). Direitos humanos e acessibilidade: desafios na educação inclusiva. Palestra proferida no I Fórum de Educação Inclusiva do Conselho Municipal da Pessoa com Deficiência COMPOD. Uberlândia: COMPOD.

Resende, A. P. C. \& Vital, F. M. P. (Orgs.) (2008). A Convenção sobre os Direitos das Pessoas com deficiência comentada. Brasília, DF: Coordenadoria Nacional para Integração da Pessoa Portadora de Deficiência - CORDE.

Sassaki, R., K. (2003). Vida independente: História, movimento, liderança, conceito, filosofia e fundamentos; reabilitação, emprego e terminologia. São Paulo: RNR.

Sassaki, R., K. (2010). Inclusão: Construindo uma sociedade para todos. Rio de Janeiro: WVA.

Silva, M. I. (2015). Estudo comparado da Lei Brasileira de Inclusão da Pessoa com Deficiência. São Paulo: SEDPcD.

Silva, L. M. G. \& Miranda, A. A. B. (2012). Inclusão escolar e deficiência: apontamentos históricos e legais. Em L. C. Silva (Org.), Inclusão Educacional, do discurso à realidade: Construções e potencialidades nos diferentes contextos educacionais (pp. 139157). Uberlândia: EDUFU.

Veiga Neto, A. (2005) Quando a inclusão pode ser uma forma de exclusão. Em A. M. Machado (Org.), Psicologia e Direitos humanos: Educação Inclusiva - Direitos Humanos na Escola. (pp. 55-70). São Paulo: Casa do Psicólogo.

Recebido em: 28/03/2016 Aprovado em: 13/04/2017

\section{Sobre as autoras}

Ana Luiza de Mendonça Oliveira (ana.oliveiraluiza@gmail.com) Graduação em Psicologia pela Universidade Federal de Uberlândia. Aluna do Programa de Pós-graduação do Instituto de Psicologia da Universidade Federal de Uberlândia.

Marineia Crosara de Resende (marineiaresende@gmail.com)

Doutorado em Educação pela Universidade Estadual de Campinas, ProfessoraAssociada I do Instituto de Psicologia da Universidade Federal de Uberlândia. 
